\title{
A reverse factual analysis of the association between smoking and memory decline in China
}

\author{
Yingying $\mathrm{Yi}^{1}$, Ying Liang ${ }^{2^{*}}$ and Guoqiang Rui ${ }^{3}$
}

\begin{abstract}
Background: Whether smoking accelerates memory recession has been a topic of significant research. However, randomised controlled trials are not easy to carry out, and does not comply with the ethics of research. And observation method which based on the most readily observed data is easy to draw the wrong conclusions without adjustment. The memory difference between smokers and non-smokers may not really represent the real differences between their memories.

Methods: In response to these limitations, we adopt propensity score method to match the samples and solve the estimated selection bias and confounding bias on elderlies aged 60 years and over based on Chinese Longitudinal Healthy Longevity Survey (2011) data. The respondents are divided into non-smokers, people who used to smoke but not now, and people who used to smoke and still now. To balance the similarity between different groups on their propensity score weighted distributions of pretreatment covariates, we use generalized boosted models to estimate the multiply treatment propensity scores.
\end{abstract}

Results: The results show that compared with non-smokers, people who used to smoke and still now respectively have a decrease $0.0283,0.0735,0.0091$ on self-evaluation memory, daily living activities, and cognitive function. People who used to smoke but not now have a decrease 0.0224 on daily living activities, while have an increase 0. 0054 and 0.0104 on self-evaluation memory, and cognitive function.

Conclusion: The PSM has considerable utility to control pre-treatment imbalances on observed covariates in non-randomised or observational data.

Keywords: Smoking, Memory decline, Reverse factual analysis, Propensity score matching

\section{Background}

China is the world's largest producer and consumer of tobacco [1]. It has 350 million smokers and accounts for $37 \%$ of global tobacco production [2]. The increasing number of smokers and consequent effects has gained public attention [3]. Many scholars identified that smoking can be related to many things, e.g. substance abuse or dependence, increased work time, social isolation, negative life events, family breakdown, child abuse, behavioural problems, family history of smoking and anxiety, etc. [4-9]. Even passive smoking also influences all

\footnotetext{
* Correspondence: njulucy66@163.com

${ }^{2}$ Department of Social Work and Social Policy, School of Social and Behavioral Sciences, Heren Charity Academy, Nanjing University, Nanjing 210023, Jiangsu Province, People's Republic of China

Full list of author information is available at the end of the article
}

life stages of Chinese elderly, including the risk of depression, daily life ability impairment, the odds of selfreported chronic diseases, and the impacts of cognitive function on social participation [10].

In recent years, researchers pay more attention to the negative impacts of smoking on working memory $[11,12]$. A longitudinal study for eight long-term smokers found the decline of their memory, cognitive function, and attention ability was closely related to smoking [13]. Compared with non-smokers, smokers have weaker performance in cognition and memory, and, in the long run, are more likely to suffer from depression and anxiety [14-18]. For adolescents, smoking does more serious damage to youths' working memories $[19,20]$. For smokers between ages 43 
and 53 who smoke more than 20 cigarettes a day, memory recession is faster than in youths [21]. For elderly smokers who smoke or smoked, compared to those who have never smoked, had more severely declining memory and cognitive functions as well as larger risk for Alzheimer's disease [22-24]. The reason is that the harmful substances in tobacco or nicotine negatively impact people's sleep quality, and consequently damage memory and cognitive functions [25]. Smokers' working memory ability and cognitive efficiency are significantly lower than nonsmokers, so people should pay attention to smoking and memory impairment [26]. However, some researchers find that working memory and ability of the shortterm smokers were improved compared to that of the non-smokers [27].

Along with aging, memory is also affected. Whether smoking accelerates memory recession has been a topic of significant research. In some studies, scholars used randomised controlled trials, so the behaviours and results of smokers and non-smokers could be easily observed. Randomised controlled trials need to recruit a large number of participants, who are then randomly assigned to smoking and non-smoking groups. Nevertheless, this type of experiment is not easy to carry out, and does not comply with the ethics of research. In this case, observation is the most appropriate method. However, based on the most readily observed data, it is easy to draw the wrong conclusions without adjustment. For example, when comparing the best memory of the smoking group and the poorest memory of the nonsmoking group, we would come to the conclusion that smoking is harmless to memory. The reason is that observation study does not adopt randomised grouping, which weakens the influence of confounding variables in the treatment and control groups. Therefore, it is easy to cause systematic bias. The Propensity Score Matching (PSM) method can solve this problem and eliminate interference factors between the two groups. This research study employed the PSM method to match samples, using the propensity score to control covariates, and solve the estimation bias caused by self-selectivity.

\section{Methods}

\section{Sample}

Research data for this study came from the latest survey data of the Chinese Longitudinal Healthy Longevity Survey (CLHLS) from 2011. The CLHLS conducted face-to-face interviews in 1998, 2002, 2005, 2008, and 2011, respectively, using internationally compatible questionnaires. The survey design investigated each centenarian in the sampled counties based on the voluntary principle, focusing on the oldest, i.e. ages 80 and older, from 631 counties of 22provinces in China. ${ }^{1}$ In order to yield a comparable sample, the CLHLS included young elderlies aged 65-79 and their aged 35-64 adult children from 2002 onward. Questionnaires included basic conditions of respondents as well as information on their social, economic backgrounds and family structures, as well as respondent self-evaluation on health status and quality of life, life style, disease, health and other detailed information. The survey project was supported by Demographic Analysis of Health Longevity in China and Duke University in 1998, the United Nations Population Fund (UNFPA) and China Social Sciences Foundation in 2002, and the China Natural Sciences Foundation and Hong Kong Research Grants Council in 2004. The CLHLS is currently the most representative micro-panel data related to elderly health, and has the largest global sample of centenarians to a report in Science. Related survey data presents high quality in terms of sample loss, accuracy of respondent age, and reliability and validity of main variables $[28,29]$.

In China, the age benchmark of sixty years is usually referred to as 'a cycle of sixty years'. China is located in the Asia Pacific region, which generally considers 60 years and older as elderly; the normal retirement age of this region is 60 years old. Therefore, in this paper, the study objects are elderly born in 1951 or before and reached 60 years and above in 2011.

\section{Measures}

In measuring the memory status of the elderly, this research study used multiple indicators to represent the different dimensions of memory in order to analyse the influence of smoking on people's memory.

\section{Self-evaluation memory}

Self-evaluation memory is a comprehensive measurement index, including respondents' subjective and objective memory status.

Survey question: 'What do you think about your own memory?'

Response coding: 'excellent', 'very good', 'good' $=1$; 'general', 'not good' $=0$.

\section{Activities of daily living}

Memory aging is seemingly normal for adults. Although it tends to inconvenience the elderly, generally speaking, it does not have a great impact on their working, learning and living. This research asked questions to the elderly to measure their daily living. Questions asked included wearing clothes, bathing, talking, waking up, doing housework, cooking, grocery shopping, taking medicine, etc.

Survey question: 'Whether health or memory causes difficulty in the completion of daily activities?'

Response coding: 'not difficult' = 1 (representing good memory); 'difficult but could still complete,' 'difficult and 
need help,' cannot complete' $=0$ (representing general or bad memory).

As long as one elderly response included 'difficult but could still complete', 'difficult and need help', 'cannot complete, that respondent was defined to have general or bad memory.

\section{Cognitive function}

The aging process is accompanied by the decline of cognitive function. Cognitive function degradation is often an early symptom of Alzheimer's disease, brain atrophy, and Parkinson's disease, which have been difficult problems for the elderly across many countries. The questionnaire drew on the internationally popular Mini-Mental State Examination (MMSE) for respondent orientation skills, immediate recall, delayed recall, structural imitation and calculation ability. Scores range from 0 to 31. Education background also influences MMSE scores [30]. Taking into account the low level of education among the elderly, this research utilised coding reflecting Cui et al. [30]. If respondents did not have a formal education, 18 points or less constituted disabled cognitive function. If respondents were educated 1-6 years, 21 points or less indicated disabled cognitive function. If respondents were educated more than 6 years, 25 points or less qualified as disabled cognitive function.

Response coding: disabled cognitive function $=0$; good cognitive function $=1$.

\section{Variables}

The core independent variable in this study was respondent smoking behaviour. Respondents were divided into non-smokers, people who used to smoke but not now, and people who used to smoke and still now. In order to investigate smoking effects on the memory of the elderly, some of the major demographic characteristics - i.e. social and economic status, family relationship and support, and lifestyle variables - were controlled. American researchers found that male smokers are weaker than female smokers in memorizing people's names, and that there is no gender difference in the effects of long-term smoking on memory ability; both males and females suffer memory deficits [31]. If the bad habits of smoking continue with aging, they cause memory disorders [32]. Therefore, demographic variables included in this research were age, gender (male coded as 1 , female coded as 0 ), residence (city coded as 1 , rural coded as 0 ), current marital status (married coded as 1 , other - unmarried, divorced, widowed - coded as 0 ), and memory-related disease diagnosis (yes coded as 1, no coded as 0). Blau and Duncan [33] observed that the level of education was an important measurement index for social and economic status as occupation and income. Given the low education of the elderly and the primary school 6-year completion requirement in China, socioeconomic status variables included years of education (more than 6 years of education coded as 2; 1-6 years coded as 1 ; not received education coded as 0 ), employment before 60 years old (had a job coded as 1 , other coded as 0 ), and self-evaluated economic level (middle, more than middle and very high coded as 1; lower and poor coded as 0). Cognitive neuroscientists at Michigan State University found that exercises, especially aerobic exercises, could improve long-term memory. In other words, people who do not exercise may not have very good memory. Researchers at Illinois State University found that older people who often exercise have better memories, and neural activities associated with cognitive activities make them more active and effective. In addition, alcohol paralyses the brain and inhibits nerve cells, which results in torpid reaction and affects the hippocampus in the brain. The hippocampus plays a key role in memory; consequently, alcohol causes declining memory [34]. Therefore, lifestyle variables included regular exercise (yes coded as 1, no coded as 0 ), and drinking habits (do not drink coded as 2, used to drink but not now coded as 1 , regular drinker coded as 0$)$.

\section{Reverse factual analysis}

PSM is a method based on reverse factual analysis applying to biology, and was put forward by Paul Rosenbaum and Donald Rubin in 1983. After the 1990s, the method was also applied in health economics and other social sciences. In observational studies, data bias and confounding variables exist due to various reasons. The basic idea of this method is that when studying the effect of a policy or behaviour, comparing similar treated and controlled groups effectively reduces sample selection biases. Compared with traditional matching methods, PSM simplifies the multi-dimension to one single dimension, which reduces computational difficulty and the large sample size requirement, as well as improves the probability of matching success [35-38]. Propensity score methods do not require modelling the mean for outcomes. Accordingly, this research only used pretreatment covariates and treatment assignments of study participants to implement propensity score adjustments, which avoided bias from model misspecification [39, 40]. Numerous studies have shown the propensity score method can be extended to multiple treatment cases [41-46]).

In the multiple treatment setting, Generalized Boosted Model (GBM) can capture complex and nonlinear relationships on pre-treatment covariates through an iterative process, finding the propensity score leading to the best balance between treatment and control groups [47]. 
That is, GBM can deal with continuous and discrete variables.

\section{Results}

\section{Sample selection and description}

Research samples were selected based on the following principles: (1) Samples were selected according to respondent birth year; samples born after 1951 were eliminated; (2) Samples missing variable values were deleted. Ultimately, there were 3311 samples, including 1000 non-smokers, 1881 smokers and 430 respondents who used to smoke but did not anymore. Table 1 shows descriptive statistics of all sample data, and compares the three groups. Table 1 shows the gender distribution was relatively balanced, with 1652 males and 1659 females. There were more males who smoked, 852, accounting for $51.57 \%$ of the subsample. Only 433 males did not smoke, accounting for $26.21 \%$; 367 males used to smoke but did not anymore, accounting for $22.22 \%$ of the male subsample. For females, only 148 smoked, equivalent to $8.92 \% .1448$ females were non-smokers, i.e. $87.28 \% .63$ females used to smoke but did not anymore, accounting for $3.80 \%$. Most respondents lived in rural areas, with 1-6 years of education, and mainly engaged in farming before 60 years of age. Furthermore, most were married, with relatively uniform self-evaluated economic levels,

Table 1 Sample description

\begin{tabular}{|c|c|c|c|c|c|c|}
\hline Variable & Value & $\begin{array}{l}\text { All samples } \\
\text { Mean(S.E.) }\end{array}$ & $\begin{array}{l}\text { Not smoke } \\
\text { Mean(S.E.) }\end{array}$ & $\begin{array}{l}\text { Used to smoke but } \\
\text { not now Mean(S.E.) }\end{array}$ & $\begin{array}{l}\text { Used to smoke } \\
\text { and still now }\end{array}$ & $P$-value \\
\hline$\overline{\text { Age }}$ & {$[60,96]$} & $69.2712(7.0622)$ & $69.5268(7.3423)$ & $69.6814(7.0001)$ & $68.6140(6.4907)$ & $0.002^{* *}$ \\
\hline \multirow[t]{2}{*}{ Gender } & 1 male & $0.4989(0.5001)$ & $0.2302(0.4211)$ & $0.8535(0.3540)$ & $0.8520(0.3553)$ & $0.000^{* * *}$ \\
\hline & 0 female & & & & & \\
\hline \multirow[t]{2}{*}{ Residence } & 1 city & $0.2184(0.4132)$ & $0.2456(0.4306)$ & $0.2698(0.4444)$ & $0.1450(0.3523)$ & $0.000^{* * *}$ \\
\hline & 0 rural & & & & & \\
\hline \multirow[t]{2}{*}{ Marriage } & 1 married & $0.6527(0.4762)$ & $0.5875(0.4924)$ & $0.7581(0.4287)$ & $0.7300(0.4442)$ & $0.000^{* * *}$ \\
\hline & 0 others & & & & & \\
\hline \multirow[t]{3}{*}{ Years of education } & 2 more than 6 years & $1.0359(0.8844)$ & $0.8767(0.8948)$ & $1.3093(0.8019)$ & $1.2180(0.8338)$ & $0.000^{* * *}$ \\
\hline & $11-6$ years & & & & & \\
\hline & 0 never be educated & & & & & \\
\hline \multirow[t]{2}{*}{ Whether had a job before 60 years old } & 1 had a job & $0.1915(0.3935)$ & $0.1834(0.3871)$ & $0.2465(0.4315)$ & $0.1830(0.3869)$ & $0.008^{* *}$ \\
\hline & 0 others & & & & & \\
\hline \multirow[t]{2}{*}{ Self-evaluation economic level } & $\begin{array}{l}1 \text { middle, more than } \\
\text { middle and very high }\end{array}$ & $0.5310(0.4991)$ & $0.5433(0.4983)$ & $0.5349(0.4994)$ & $0.5060(0.5002)$ & 0.159 \\
\hline & 0 lower and poor & & & & & \\
\hline \multirow[t]{2}{*}{ Whether have regular exercises } & 1 yes & $0.3781(0.4850)$ & $0.3828(0.4862)$ & $0.3605(0.4807)$ & $0.3770(0.4849)$ & 0.688 \\
\hline & 0 no & & & & & \\
\hline \multirow[t]{3}{*}{ Whether often drink } & 2 has not been drinking & $1.4400(0.8458)$ & $1.7326(0.6418)$ & $1.0930(0.8906)$ & $1.0390(0.9383)$ & $0.000^{* * *}$ \\
\hline & $\begin{array}{l}1 \text { used to drinking but } \\
\text { not now }\end{array}$ & & & & & \\
\hline & 0 has been drinking & & & & & \\
\hline \multirow{2}{*}{$\begin{array}{l}\text { Whether have been diagnosed with } \\
\text { memory-related disease(yes coded } \\
\text { as } 1 \text { and no coded as } 0 \text { ) }\end{array}$} & 1 yes & $0.0233(0.1478)$ & $0.0202(0.1407)$ & $0.0326(0.1777)$ & $0.0220(0.1468)$ & 0.293 \\
\hline & 0 no & & & & & \\
\hline \multirow[t]{2}{*}{ Self-evaluation memory } & $\begin{array}{l}1 \text { excellent, very good, } \\
\text { good }\end{array}$ & $0.1444(0.3515)$ & $0.1478(0.3550)$ & $0.1512(0.3586)$ & $0.1350(0.3419)$ & 0.592 \\
\hline & 0 general, not good & & & & & \\
\hline \multirow[t]{2}{*}{ Daily living abilities } & 1 good & $0.5630(0.4961)$ & $0.5529(0.4973)$ & $0.5372(0.4992)$ & $0.5930(0.4915)$ & 0.061 \\
\hline & 0 general, not good & & & & & \\
\hline \multirow[t]{2}{*}{ Cognitive function } & 1 good & $0.3328(0.4713)$ & $0.3721(0.4835)$ & $0.2651(0.4419)$ & $0.2880(0.4531)$ & $0.000^{* * *}$ \\
\hline & 0 disabled & & & & & \\
\hline Sample size & - & 3311 & 1881 & 430 & 1000 & - \\
\hline
\end{tabular}


Table 2 Balance of the treatment and comparison groups

\begin{tabular}{|c|c|c|c|c|c|c|c|}
\hline & Var & $E(Y 1 \mid t=1)$ & $\mathrm{E}(\mathrm{YO} \mid \mathrm{t}=1)$ & KS & $P$ & Control & Stop.method \\
\hline 1 & Age & 69.527 & 68.614 & 0.073 & 0.002 & Used to smoke and still now & Unw \\
\hline 2 & Edu & 0.877 & 1.218 & 0.207 & 0.000 & Used to smoke and still now & Unw \\
\hline 3 & Marital & 0.587 & 0.730 & 0.143 & 0.000 & Used to smoke and still now & Unw \\
\hline 4 & Gender & 0.230 & 0.852 & 0.622 & 0.000 & Used to smoke and still now & Unw \\
\hline 5 & Living & 0.246 & 0.145 & 0.101 & 0.000 & Used to smoke and still now & Unw \\
\hline 6 & Income & 0.543 & 0.506 & 0.037 & 0.313 & Used to smoke and still now & Unw \\
\hline 7 & Work & 0.183 & 0.183 & 0.000 & 1.000 & Used to smoke and still now & Unw \\
\hline 8 & Exercise & 0.383 & 0.377 & 0.006 & 1.000 & Used to smoke and still now & Unw \\
\hline 9 & Illness & 0.020 & 0.022 & 0.002 & 1.000 & Used to smoke and still now & Unw \\
\hline 10 & drink & 1.733 & 1.039 & 0.381 & 0.000 & Used to smoke and still now & Unw \\
\hline 11 & Age & 69.527 & 69.681 & 0.037 & 0.700 & Used to smoke but not now & Unw \\
\hline 12 & Edu & 0.877 & 1.309 & 0.255 & 0.000 & Used to smoke but not now & Unw \\
\hline 13 & Marital & 0.587 & 0.758 & 0.171 & 0.000 & Used to smoke but not now & Unw \\
\hline 14 & Gender & 0.230 & 0.853 & 0.623 & 0.000 & Used to smoke but not now & Unw \\
\hline 15 & Living & 0.246 & 0.270 & 0.024 & 0.983 & Used to smoke but not now & Unw \\
\hline 16 & Income & 0.543 & 0.535 & 0.008 & 1.000 & Used to smoke but not now & Unw \\
\hline 17 & Work & 0.183 & 0.247 & 0.063 & 0.117 & Used to smoke but not now & Unw \\
\hline 18 & Exercise & 0.383 & 0.360 & 0.022 & 0.993 & Used to smoke but not now & Unw \\
\hline 19 & Illness & 0.020 & 0.033 & 0.012 & 1.000 & Used to smoke but not now & Unw \\
\hline 20 & drink & 1.733 & 1.093 & 0.394 & 0.000 & Used to smoke but not now & Unw \\
\hline 21 & Age & 69.527 & 69.293 & 0.031 & 0.990 & Used to smoke and still now & Es.mean \\
\hline 22 & Edu & 0.877 & 0.855 & 0.022 & 1.000 & Used to smoke and still now & Es.mean \\
\hline 23 & Marital & 0.587 & 0.587 & 0.000 & 1.000 & Used to smoke and still now & Es.mean \\
\hline 24 & Gender & 0.230 & 0.247 & 0.017 & 1.000 & Used to smoke and still now & Es.mean \\
\hline 25 & Living & 0.246 & 0.199 & 0.046 & 0.779 & Used to smoke and still now & Es.mean \\
\hline 26 & Income & 0.543 & 0.532 & 0.011 & 1.000 & Used to smoke and still now & Es.mean \\
\hline 27 & Work & 0.183 & 0.173 & 0.010 & 1.000 & Used to smoke and still now & Es.mean \\
\hline 28 & Exercise & 0.383 & 0.365 & 0.018 & 1.000 & Used to smoke and still now & Es.mean \\
\hline 29 & Illness & 0.020 & 0.016 & 0.004 & 1.000 & Used to smoke and still now & Es.mean \\
\hline 30 & drink & 1.733 & 1.715 & 0.011 & 1.000 & Used to smoke and still now & Es.mean \\
\hline 31 & Age & 69.527 & 70.015 & 0.068 & 0.785 & Used to smoke but not now & Es.mean \\
\hline 32 & Edu & 0.877 & 0.888 & 0.029 & 1.000 & Used to smoke but not now & Es.mean \\
\hline 33 & Marital & 0.587 & 0.587 & 0.000 & 1.000 & Used to smoke but not now & Es.mean \\
\hline 34 & Gender & 0.230 & 0.264 & 0.034 & 1.000 & Used to smoke but not now & Es.mean \\
\hline 35 & Living & 0.246 & 0.215 & 0.031 & 1.000 & Used to smoke but not now & Es.mean \\
\hline 36 & Income & 0.543 & 0.565 & 0.022 & 1.000 & Used to smoke but not now & Es.mean \\
\hline 37 & Work & 0.183 & 0.184 & 0.000 & 1.000 & Used to smoke but not now & Es.mean \\
\hline 38 & Exercise & 0.383 & 0.364 & 0.019 & 1.000 & Used to smoke but not now & Es.mean \\
\hline 39 & Illness & 0.020 & 0.014 & 0.006 & 1.000 & Used to smoke but not now & Es.mean \\
\hline 40 & drink & 1.733 & 1.727 & 0.010 & 1.000 & Used to smoke but not now & Es.mean \\
\hline 41 & Age & 69.527 & 69.458 & 0.037 & 0.933 & Used to smoke and still now & Ks.max \\
\hline 42 & Edu & 0.877 & 0.854 & 0.027 & 0.997 & Used to smoke and still now & Ks.max \\
\hline 43 & Marital & 0.587 & 0.567 & 0.020 & 1.000 & Used to smoke and still now & Ks.max \\
\hline 44 & Gender & 0.230 & 0.251 & 0.021 & 1.000 & Used to smoke and still now & Ks.max \\
\hline
\end{tabular}


Table 2 Balance of the treatment and comparison groups (Continued)

\begin{tabular}{|c|c|c|c|c|c|c|c|}
\hline 45 & Living & 0.246 & 0.209 & 0.037 & 0.934 & Used to smoke and still now & Ks.max \\
\hline 46 & Income & 0.543 & 0.521 & 0.022 & 1.000 & Used to smoke and still now & Ks.max \\
\hline 47 & Work & 0.183 & 0.192 & 0.009 & 1.000 & Used to smoke and still now & Ks.max \\
\hline 48 & Exercise & 0.383 & 0.348 & 0.035 & 0.955 & Used to smoke and still now & Ks.max \\
\hline 49 & Illness & 0.020 & 0.016 & 0.004 & 1.000 & Used to smoke and still now & Ks.max \\
\hline 50 & drink & 1.733 & 1.704 & 0.015 & 1.000 & Used to smoke and still now & Ks.max \\
\hline 51 & Age & 69.527 & 69.457 & 0.049 & 0.991 & Used to smoke but not now & Ks.max \\
\hline 52 & Edu & 0.877 & 0.889 & 0.028 & 1.000 & Used to smoke but not now & Ks.max \\
\hline 53 & Marital & 0.587 & 0.609 & 0.022 & 1.000 & Used to smoke but not now & Ks.max \\
\hline 54 & Gender & 0.230 & 0.251 & 0.021 & 1.000 & Used to smoke but not now & Ks.max \\
\hline 55 & Living & 0.246 & 0.205 & 0.041 & 0.999 & Used to smoke but not now & Ks.max \\
\hline 56 & Income & 0.543 & 0.592 & 0.049 & 0.992 & Used to smoke but not now & Ks.max \\
\hline 57 & Work & 0.183 & 0.171 & 0.012 & 1.000 & Used to smoke but not now & Ks.max \\
\hline 58 & Exercise & 0.383 & 0.361 & 0.022 & 1.000 & Used to smoke but not now & Ks.max \\
\hline 59 & Illness & 0.020 & 0.006 & 0.014 & 1.000 & Used to smoke but not now & Ks.max \\
\hline 60 & drink & 1.733 & 1.777 & 0.022 & 1.000 & Used to smoke but not now & Ks.max \\
\hline
\end{tabular}

Note: Unw represents unweighted method. Es.mean and Ks.max respectively use the effect size or the absolute standardized bias and summarizes across variables with the mean, and use the KS statistics to assess balances and summarizes using the maximum across variables

and most did not exercise often. Fewer individuals drank at the time of the survey, and non-smokers always do not drink.

For all samples, the mean values of self-evaluated memory, daily living abilities, and cognitive function were $0.1444,0.5630$ and 0.3328 , respectively. Nonsmokers were the best in cognitive function. People who used to smoke but did not anymore were the best in self-evaluated memory. People who smoked were the best in daily living abilities. This research used the F test to find that differences of self-evaluated memory among the three groups were not significant $(0.1 \%$ significance), while differences of daily living abilities were $10 \%$ significant.

\section{Balancing the treated and controlled groups}

These three respective elderly groups exhibited good performances in one certain aspect, we could not infer that smoking declines memory. This relationship may have been endogenous, so comparing the three groups directly would lead to estimation bias because residual error may include 'disease' factors which are related to smoking but cannot be controlled by observable variables. Therefore, the effects of smoking on memory may be exaggerated or reduced [48]. As a result, this researchused generalized boosted regression to estimate propensity scores and weighting of compared cases to estimate the average treatment effect on the treated group.

The study utilised two methods to assess the balance, or equivalence, established on pre-treatment covariates of the weighted treatment and control groups [47]. One method was to use the effect size or the absolute standardised bias and summarize across variables with the mean; the other method was to use KolmogorovSmirnov (KS) statistics to assess balances and summarise using the maximum across variables. 5000 iterations were taken to be the optimal number for minimising the largest of KS statistics. Table 2 shows how well the weights succeeded in manipulating the control group to match or balance characteristics of the two groups. In Table $2, \mathrm{E}(\mathrm{Y} 1 \mid \mathrm{t}=1)$ and $\mathrm{E}(\mathrm{Y} 0 \mid \mathrm{t}=1)$ respectively represent the treatment means and the control means for each of the covariables, while $K S$ and $P$ are the Kolmogorov-Smirnov test statistic and its associated $p$-value. $P$-value is derived from Monte Carlo simulations for the maximum KS statistic. Thus, a small $p$-value indicates the groups are clearly imbalanced and inconsistent with what should be expected had the groups been formed by random assignment. From Table 2, it is evident balance was achieved after weighting.

In order to demonstrate the importance and rationale of the PSM method in empirical research, useful diagnostic plots from propensity score objects were generated (see Fig. 1). Figure 1 is the standardised effect size plot illustrating the effect of weights on the magnitude of differences among groups on each covariate. The standardised effect size is defined as the treatment group mean minus the control group mean divided by the treatment group standard deviation. In these plots, closed circles indicate a statistically significant difference. Figure 1 shows many differences occurred before 


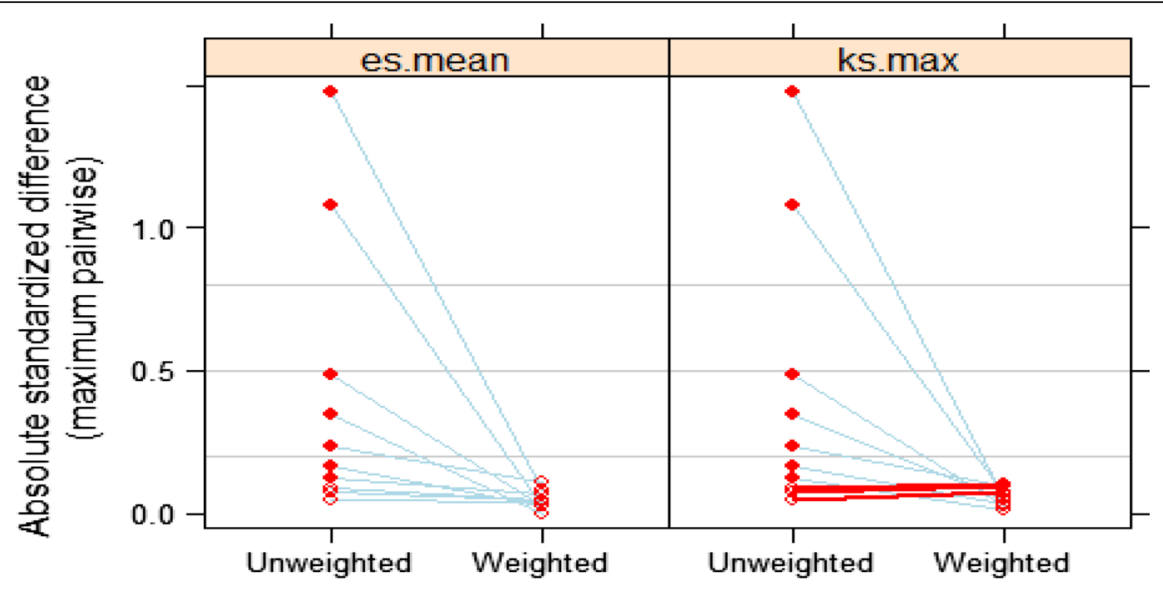

Balance for used to smoke and still now versus unweighted not smoke

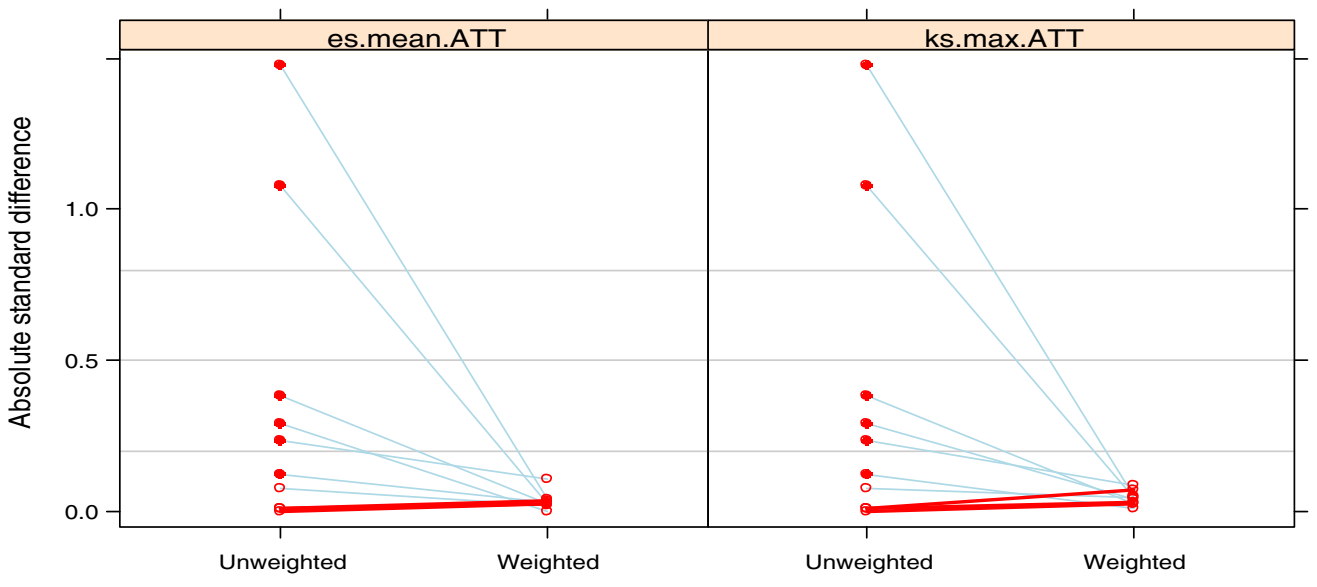

Balance for used to smoke but not now versus unweighted not smoke

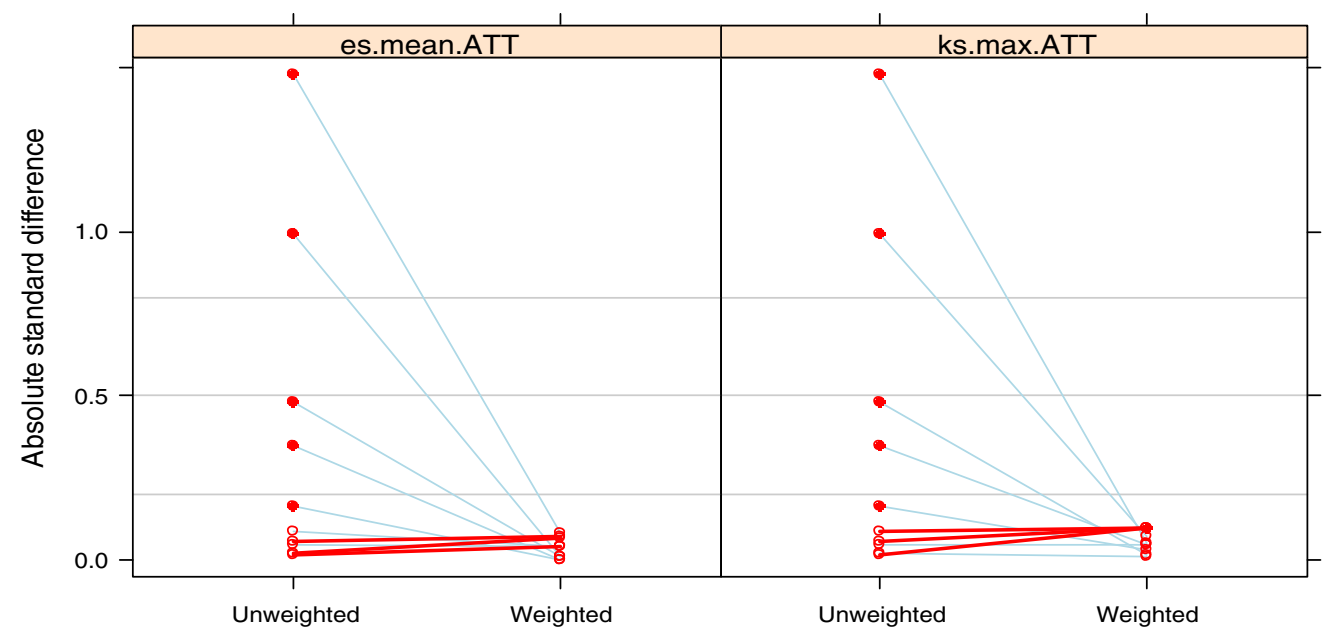

Fig. 1 The standardized effect size plots before and after weighting 
weighting, while none occurred after weighting. Furthermore, effect sizes of most variables were reduced after weighting (referring to the blue lines in Fig. 1).

\section{Estimation results}

In non-randomized trials, the PSM method can maximize the elimination of sample selection bias and confounding bias [49]. As shown in Table 3, compared with non-smokers, the analysis estimated a decrease in self-evaluated memory of 0.0283 for smokers and an increase of 0.0054 for former smokers. For daily living activities, both groups decreased by 0.0735 and 0.0224 , respectively. For cognitive function, the analysis estimated a 0.0091 decrease for smokers and a 0.0104 increase for former smokers. However, except for the effect on continued smokers in daily living activities, other effects did not appear to be statistically significant.

\section{Discussion}

Smoking is a widespread and serious issue in China. It has a certain sociality and function in social communication. However, smoking is harmful to people's physical and mental health. Previous studies have indicated positive or negative expectations of smoking can affect smokers' decisions, intentions and behaviours. Those with positive expectations of smoking believe smoking can promote social interaction, so most smoke and are not willing to give up the habit. Positive expectations can effectively predict the consequences of nicotine dependence [50]. Those who hold negative expectations of smoking worry about being rejected by peers if they smoke, so few smoke $[51,52]$.

This paper aimed to research whether smoking affects memory. The PSM was employed to reduce or eliminate confounding characteristics in observational data for smokers and non-smokers. PSM has gained widespread application over the past decade because of its advantages

Table 3 Analysis of outcomes

\begin{tabular}{cllll}
\hline Var1: Self-evaluation memory & Estimate & Std.Error & T value & $\operatorname{Pr}(>|t|)$ \\
Intercept & 0.1478 & 0.0082 & 18.059 & $0.000^{* * *}$ \\
Used to smoke and still now & -0.0283 & 0.0230 & -1.232 & 0.218 \\
Used to smoke but not now & 0.0054 & 0.0383 & 0.141 & 0.888 \\
Var2: Daily living abilities & Estimate & Std.Error & T value & $\operatorname{Pr}(>|t|)$ \\
Intercept & 0.5529 & 0.0115 & 48.222 & $0.000^{* * *}$ \\
Used to smoke and still now & -0.0735 & 0.0357 & -2.057 & $0.034^{*}$ \\
Used to smoke but not now & -0.0224 & 0.0531 & -0.422 & 0.672 \\
Var3: Cognitive function & Estimate & Std.Error & T value & $\operatorname{Pr}(>|t|)$ \\
Intercept & 0.3721 & 0.0111 & 33.385 & $0.000^{* * *}$ \\
Used to smoke and still now & -0.0091 & 0.0346 & -0.262 & 0.793 \\
Used to smoke but not now & 0.0104 & 0.0525 & 0.198 & 0.843 \\
\hline
\end{tabular}

Note: $10 \%$ significance level; *5 \% significance level; **1 \% significance level; ***1 \% significance level compared with traditional regression methods. PSM uses propensity score weights to control pre-treatment imbalances on observed covariates in non-randomised or observational data. After balancing or weighting, confounding characteristics are reduced or eliminated, and the distributions of observed pre-treatment characteristics are similar among the treated and controlled groups. This research study used propensity scores to weight the samples for the treatment group (non-smokers) and control group (current and former smokers).

Results showed that compared with non-smokers, current smokers decreased scores by $0.0283,0.0735,0.0091$, respectively, on self-evaluated memory, daily living activities, and cognitive function. In contrast, former smokers decreased daily living activities by 0.0224 , while they increased self-evaluated memory and cognitive function by 0.0054 and 0.0104 , respectively. However, most effects did not appear to be statistically significant, except for the effect on daily living activities in current smokers. When people quit smoking, their self-evaluation and cognitive functions improve. Research results were generally insignificant in elderly Chinese samples. Possible causes include: (1) memory is affected by many factors, e.g. genetics, work demands, psychosomatic diseases, etc.; (2) this research used a three-level ordinal variable other than smoking history to measure smoking; (3) cognitive function related to coding in Chinese context. Although the education variable was added to adjust coding, respondent answers may also have had measurement error; and (4) the research sample consisted of elderly aged 60 and over, consequently, smoking may not have only related to their present life but also to their early childhood, adolescence, and adult lives.

Aging is becoming an increasingly serious problem in contemporary China. Due to smoking, elderly vulnerable groups bear significantly more health risks, which increases their children's economic and personal care burdens [53, 54]. Furthermore, social burdens [55-59] and social pressure [60-62] also increse. Therefore, prohibiting campaign should be promoted.

\section{Conclusion}

This study also had limitations: (1) Respondents were divided into three types: non-smokers, former smokers, and current smokers. In order to deeply mine the relationships between smoking and memory, future research could include a smoking frequency variable instead of a three-level variable. However, the current research lacked more detailed smoking indexes, e.g. the quality of cigarettes, combined index of the number of cigarettes and time. (2) The current study extracted three factors to denote memory: self-evaluated memory, daily living abilities, and cognitive function. However, these indexes were obtained through self-assessment, which may have had measurement error. In fact, accurately measuring 
memory is difficult. (3) The PSM only remove confounding by observed variables, that is, if there are some unmeasured variables differ among the treatment group and the control group, then the estimate may be biased. And the gender is very different between smokers and non-smokers in Table 1 , perhaps gender is a main influence factor for memory loss. However, the PSM cannot reflect this difference. Therefore, in order to obtain more information on smoking and memory, further studies are needed.

\section{Endnotes}

${ }^{1}$ The 22 provinces include Liaoning, Jilin, Heilongiiang, Hebei, Beijing, Tianjin, Shanxi, Shannxi, Shanghai, Jiangsu, Zhejiang, Anhui, Fujian, Jiangxi, Shandong, Henan, Hubei, Hunan, Guangdong, Guangxi, Sichuan, and Chongqing.

\section{Acknowledgements}

The authors gratefully acknowledge the Center who provided CLHLS data and questionnaires. This paper is supported by the National Natural Science Funds for Excellent Young Scholar of 2016 (71622013): Social Security and Public Policy, the Key Project of National Social Science Fund (16AZZ014), the General Program of National Natural Science Foundation of China (71473117 and 71173099), Project of Education Bureau of Jiangsu Province (2015ZDAXM007), and the Deng Feng Scholars Program in 2016.

\section{Availability of data and material}

Click here for CLHLS data and questionnaires

[http://centerforaging.duke.edu/index.php?option=com_content\&view= article\&id=115\&ltemid $=152]$.

\section{Authors' contributions}

YYY conceived of and designed the study, analysed and interpreted the data and drafted the manuscript. YL designed the study, assisted in interpreting the data and helped to draft the manuscript. GQR revised the manuscript. All authors read and approved the final manuscript.

\section{Competing interests}

The authors declare that they have no competing interests.

\section{Author details}

'School of Economics, Nanjing University of Posts and Telecommunications, Nanjing 210023, Jiangsu Province, People's Republic of China. ${ }^{2}$ Department of Social Work and Social Policy, School of Social and Behavioral Sciences, Heren Charity Academy, Nanjing University, Nanjing 210023, Jiangsu Province, People's Republic of China. ${ }^{3}$ ShiLiang School of Law, Changzhou University, Changzhou 213164, Jiangsu Province, People's Republic of China.

Received: 24 February 2016 Accepted: 1 August 2016

Published online: 22 August 2016

\section{References}

1. World Health Organization. Global adult tobacco survey. Geneva: World Health Organization; 2010.

2. Shafey O, Ericksen M, Ross $\mathrm{H}$, et al. The tobacco atlas. 3rd ed. Atlanta: The American Cancer Society; 2009

3. Lopez AD, Mathers CD, Ezzati M, et al. Global and regional burden of disease and risk factors, 2001: systematic analysis of population health data. Lancet. 2006;367:1747-57.

4. Almeida OP, Pfaff JJ. Depression and smoking amongst older general practice patients. J Affect Disord. 2005;86(2-3):317-21.

5. Duncan B, Rees DI. Effect of smoking on depressive symptomatology: a reexamination of data from the National Longitudinal Study of Adolescent Health. Am J Epidemiol. 2005;162(5):461-70.

6. Fergusson DM, Goodwin RD, Horwood LJ. Major depression and cigarette smoking: results of a 21-year longitudinal study. Psychol Med. 2003;33(8):1357-67.
7. Lee Ridner S, Staten RR, Danner FW. Smoking and depressive symptoms in a college population. J Sch Nurs. 2005;21:229-35.

8. Linares Scott TJ, Heil SH, Higgins ST, et al. Depressive symptoms predict smoking status among pregnant women. Addict Behav. 2009;34(8):705-8,

9. Liang Y, Guo ML. Utilization of health services and health-related quality of life research of rural-to-urban migrants in China: a cross-sectional analysis. Soc Indic Res. 2015;120(1):277-95. doi:10.1007/s11205-014-0585-y.

10. Wang WJ, Zeng Y, Lu JH. Passive smoking and its health risk among Chinese elderly: a life course perspective. Popul Res. 2014;38(1):98-112.

11. Pineda JA, Herrera C, Kang C, et al. Effects of cigarette smoking and 12-h abstention on working memory during a serial-probe recognition task. Psychopharmacology. 1998;139:311-21.

12. Ashare RL, Wileyto EP, Ruparel $K$, et al. Effects of tolcapone on working memory and brain activity in abstinent smokers: a proof-of-concept study. Drug Alcohol Depend. 2013;133:852-6.

13. Xu JS, Mendrek A, Cohen MS, et al. Brain activity in cigarette smokers performing a working memory task: effect of smoking abstinence. Biol Psychiatry. 2005;58(2):143-50.

14. Andersson K, Hockey GR. Effects of cigarette smoking on incidental memory. Psychopharmacology. 1977;52:223-6.

15. Parrott AC. Nicotine psychobiology: how chronic-dose prospective studies can illuminate some of the theoretical issues from acute-dose research. Psychopharmacology (Berlin). 2006;184(3-4):567-76.

16. Heffernan TM, O'Neill TS, Moss M. Smoking and everyday prospective memory: a comparison of self-report and objective methodologies. Drug Alcohol Depend. 2010;112:234-8.

17. Heffernan TM, O'Neill TS, Moss M. Smoking-related prospective memory deficits in a real-world task. Drug Alcohol Depend. 2012;120:1-6.

18. Liang Y. Satisfaction with economic and social rights and quality of life in a post-disaster zone in china: evidence from earthquake-prone Sichuan. Disaster Med Public Health Prep. 2015;9(2):111-8. doi:10.1017/dmp.2015.7.

19. Jacobsen LK, Mencl WE, Constable RT, et al. Impact of smoking abstinence on working memory neurocircuitry in adolescent daily tobacco smokers. Psychopharmacology. 2007;193:557-66.

20. Lien L, Sagatun A, Heyerdahl S, et al. Is the relationship between smoking and mental health influenced by other unhealthy lifestyle factors? Results from a 3-Year follow-up study among adolescents in Oslo, Norway. J Adolesc Health. 2009:45(9):609-17.

21. Nooyens AC, VanGelder BM, Verschuren WM. Smoking and cognitive decline among middle-aged men and women: the Doetinchem Cohort Study. Am J Public Health. 2008;98:2244-50.

22. Tyas $S L$, White $L R$, Petrovitch $H$, et al. Mid-life smoking and late-life dementia: the Honolulu-Asia Aging Study. Neurobiol Aging. 2003;24(3):589-96.

23. Almeida OP, Garrido GJ, Alfonso H, et al. 24-Month effect of smoking cessation on cognitive function and brain structure in later life. Neuroimage. 2011;55(4):1480-9.

24. Peters R. Blood pressure, smoking and alcohol use, association with vascular dementia. Exp Gerontol. 2012;47(5):865-72.

25. Jaehne A, Unbehaun T, Feige B, et al. How smoking affects sleep: a polysomnographical analysis. Sleep Med. 2012;13(12):1286-92.

26. Sutherland MT, Ross TJ, Shakleya DM, et al. Chronic smoking, but not acute nicotine administration, modulates neural correlates of working memory. Psychopharmacology. 2011;213:29-42.

27. Patterson F, Jepson C, Loughead J, et al. Working memory deficits predict short-term smoking resumption following brief abstinence. Drug Alcohol Depend. 2010;106:61-4.

28. Zeng Y, Gu D. Reliability of Age Reporting Among the Chinese Oldest-old in the CLHLS Datasets. In: Zeng Y, Poston DL, D.A. Vlosk D.Gu, editors. 2008;20: 61-78.

29. Gu D. Data assessment of the Chinese longitudinal healthy longevity survey in 2002. In: Zeng Y, Poston DL, Vlosk DA, Gu D, editors. Healthy longevity in china: demographic, socioeconomic, and psychological dimensions. Dordrecht: Springer; 2008. p. 39-58.

30. Cui GH, Yao YH, Xu RF, et al. Cognitive impairment using education-based cutoff points for CMMSE scores in elderly Chinese people of agricultural and Rural Shanghai China. Acta Neurol Scand. 2011;6:361-7.

31. Wan L, Friedman BH, Boutros NN, et al. Smoking status affects men and women differently on schizotypal traits and cognitive failures. Personal Individ Differ. 2008;44:425-35. 
32. Lantz AS, Lilja B, Elmstahl S. Cerebral perfusion deficits in age-associated memory impairment. The role of tobacco smoking. Aging Clin Exp Res. 2002;14(2):108-16.

33. Blau PM, Duncan OD. The American occupational structure. New York: Wiley; 1967.

34. Chopra K, Tiwari V. Alcoholic neuropathy: possible mechanisms and future treatment possibilities. Br J Clin Pharmacol. 2012;73(3):348-62.

35. Morgan S, Winship C. Counterfactuals and causal inference: methods and principles for social research. Cambridge: Cambridge University Press; 2007.

36. Fu AZ. Editorial comment on: the long-term relationship between a real change in prostate volume and a significant change in lower urinary tract symptom severity in population-based men: The Krimpen Study. Eur Urol. 2008;53(4):819-27.

37. Lian GY, Lai JH, Zheng WS. Spatial-temporal consistent labeling of tracked pedestrians across non-overlapping camera views. Pattern Recogn. 2011;44(5):1121-36.

38. Guo YF, Yu M, Sun YC. Study on an improved robust algorithm for feature point matching. Phys Procedia. 2012;33:1810-6.

39. Rubin DB. Using propensity scores to help design observational studies: application to tobacco litigation. Health Serv Outcome Res Methodol. 2001;2:169-88

40. Ho DE, Imai K, King G, et al. Matching as nonparametric preprocessing for reducing model dependence in parametric causal inference. Polit Anal. 2007;15:199-236.

41. Imbens GW. The role of the propensity score in estimating dose-response functions. Biometrika. 2000;87(3):706-10.

42. Imai K, van Dyk DA. Causal inference with general treatment regimes: generalizing the propensity score. J Am Stat Assoc. 2004;99(467):854-66.

43. Frolich M. Programme evaluations with multiple treatments. J Econ Surv. 2004;18(2):181-224.

44. Robins JM, Hernan MA, Brumback B. Marginal structural models and causal inference in epidemiology. Epidemiology. 2000;11:550-60.

45. Lechner M. Identification and estimation of causal effects of multiple treatments under the conditional independence assumption. Econ Eval Labour Market Policies. 2001;13:43-58.

46. Zanutto E, Lu B, Hornik R. Using propensity score subclassification for multiple treatment doses to evaluate a national antidrug media campaign. J Educ Behav Stat. 2005:30(1):59-73.

47. McCaffrey DF, Griffin BA, Almirall D, et al. A Tutorial on propensity score estimation for multiple treatments using generalized boosted models. Stat Med. 2013;32(19):3388-414

48. Chen Y, Liu YY. An analysis of the effectiveness of labor contracts on migrants' income. Chin Econ Q. 2010;9(2):687-712.

49. Agostino RB. Propensity score methods for bias reduction in the comparison of a treatment to a nonrandomized control group. Stat Med. 1998;17(19):2265-81.

50. Cepeda-Benito A, Reig FA. Smoking consequences questionnaire-Spanish. Psychol Addict Behav. 2000;14(3):219-30.

51. Shore TH, Tashchian A, Adams JS. Development and validation of a scale measuring attitudes toward smoking. J Soc Psychol. 2000;140(5):615-23.

52. Unger JB, Rohrbach LA, Howard-Pitney B, et al. Peer influences and susceptibility to smoking among California adolescents. Subst Use Misuse. 2001;36(5):551-71.

53. Liang $Y$, Guo M. Utilization of health services and health-related quality of life research of rural-to-urban migrants in China: a cross-sectional analysis. Soc Indic. Res. 2015;120(1):277-95

54. Liang Y, Cao R. Employment assistance policies of Chinese government play positive roles! The impact of post-earthquake employment assistance policies on the health-related quality of life of Chinese earthquake populations. Soc Indic. Res. 2015;120(3):835-57.

55. Liang Y, Chu P, Wang X. Health-related quality of life of Chinese earthquake survivors: a case study of five hard-hit disaster counties in Sichuan. Soc Indic. Res. 2014;119(2):943-66

56. Liang Y. Satisfaction with economic and social rights and quality of life in a post-disaster zone in China: evidence from earthquake-prone Sichuan. Disaster Med Public Health Preparedness. 2015;9(2):111-18.

57. Liang Y. Correlations between health-related quality of life and interpersonal trust: Comparisons between two generations of Chinese rural-to-urban migrants. Soc Indic. Res. 2015;123(3):677-700.
58. Liang Y, Lu P. Health-related quality of life and the adaptation of residents to harsh post-earthquake conditions in China. Disaster Med Public Health Preparedness. 2014;8(5):390-96.

59. Liang Y, Wang P. Influence of prudential value on the subjective well-being of Chinese urban-rural residents. Soc Indic. Res. 2014;118(3):1249-267.

60. Liang Y. Trust in chinese government and quality of life (qol) of sichuan earthquake survivors: does trust in government help to promote qol?. Soc Indic Res. 2016;127(2):541-564.

61. Liang $Y$, Yi Y, Sun Q. The impact of migration on fertility under china's underlying restrictions: a comparative study between permanent and temporary migrants. Soc Indic Res. 2014;116(1):307-326.

62. Liang Y, Zhu D. Subjective well-being of chinese landless peasants in relatively developed regions: measurement using panas and swls. Soc Indic Res. 2014;123(3):1-19.

\section{Submit your next manuscript to BioMed Central and we will help you at every step:}

- We accept pre-submission inquiries

- Our selector tool helps you to find the most relevant journal

- We provide round the clock customer support

- Convenient online submission

- Thorough peer review

- Inclusion in PubMed and all major indexing services

- Maximum visibility for your research

Submit your manuscript at www.biomedcentral.com/submit
Biomed Central 